\section{HONOURS, AWARDS, APPOINTMENTS}

Policy and Public Affairs Director The BDTA has appointed Edmund Proffitt to fill its newly created position, Policy and Public Affairs Director.

\section{Orthodontic Consultant}

Dr Sunil Hirani, a specialist orthodontist and founder of SmileLux, an orthodontic practice in Milton Keynes, has been appointed Clinical Advisor at Smilelign, a company offering an invisible orthodontic aligner system.

\section{Chairman}

Sir Stuart Rose has been appointed Chairman of private dental care provider Oasis.

\section{Young Endodontist}

First prize for the Young Dentist Endodontic Award 2013 went to Jamie Nelson from Essex; second place to Rupal Shah from Birmingham and third place to Lydia Harris from Bristol. The three winning entries involved young patients for whom the loss of a tooth would have been extremely detrimental.

\section{Practice of the year}

Honesty Dental Care in Shipley are the 2013 winners of the BDA's Good Practice Scheme Practice of the Year Award. The team will be presented with their award by BDA President Dr Barry McGonigle at a reception in December.

\section{BDA PEC}

General dental practitioner Tim Harker has been announced as the newest member of the BDA's Principal Executive Committee (PEC). Dr Harker won a by-election for the Wales seat on the BDA's governing body.

\section{Excellence award hat trick}

Dr Barry Quinn, Dr David Radford and Dr Jorge Tricio Pesce, all of King's College London Dental Institute, were awarded the Association of Dental Education of Europe (ADEE) Excellence in Dental Education award at the 2013 conference in Birmingham.

\section{Associate Professor}

Malcolm Bruce, Director of the Simulated Dental Learning Environment, has been promoted to the post of Associate Professor (Senior Lecturer) at Plymouth University Peninsula Schools of Medicine and Dentistry.

\section{Associate Professor}

Dental and maxillofacial radiology trainee Christopher Greenall of Cardiff Dental Hospital and School has been awarded the British Society of Head and Neck Imaging 2013 prize for his presentation 'Pain by ear' which was on the subject 'referred otalgia'. This is the first time the prize has gone to a dental trainee.

\section{Business Woman of the Yea}

Helen Wigglesworth, Co-Owner and Group Financial Director of Quadralene, the parent company of infection control product manufacturer Dentisan, has been shortlisted for the Vitalise Business Woman of the Year 2013 Award.

\title{
FIRST ORAL CANCER MASTERS BEGINS
}

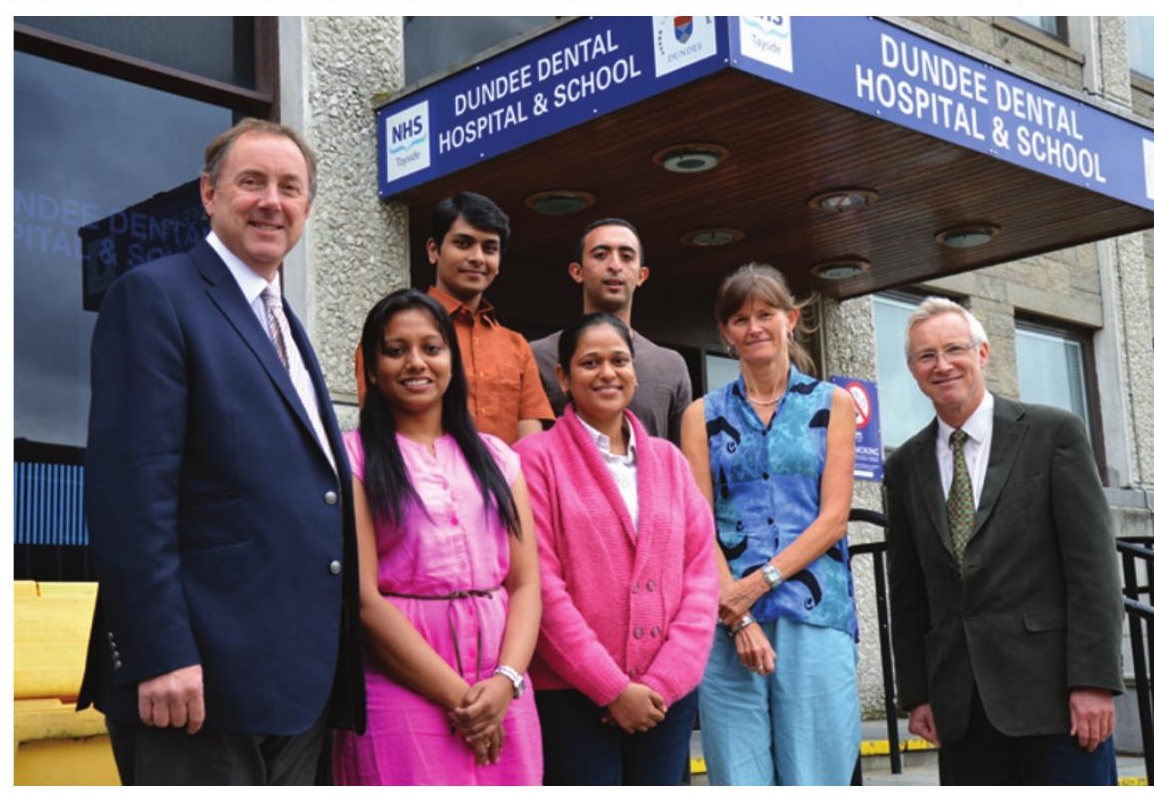

The University of Dundee's first cohort to focus on oral cancer has begun its challenging 12-month MRes Oral Cancer programme. Working alongside internationally renowned scientists and clinicians, a group of four international students will develop a sound understanding of fundamental and applied cancer biology, the aetiology, diagnosis and management of oral cancer, plus valuable experience in executing a robust laboratory-focused molecular oncology research project. Three of the students are from India and one from Egypt. The course gives them the opportunity to focus on a discipline where demand in their home countries for expertise far exceeds the availability of specialists.

\section{Regenerative dentistry}

Another new course has begun this autumn, at King's College London: a Masters in Regenerative dentistry. This one-year nonclinical course, the first of its kind in the world, covers the latest advances in stem cell and genome biology relevant to dentistry and provides practical training in dental stem cell research. The first cohort consists of seven students.

\section{BDTA TO BECOME BDIA}

During October's BDTA Dental Showcase in Birmingham, the BDTA announced that it is changing its name from the British Dental Trade Association to the British Dental Industry Association (BDIA), effective from 1 January 2014.

BDTA President Terry Porter said: 'The re-naming of the Association to the British Dental Industry Association is a milestone marking the change in membership that has taken place in recent years. There has been a widening of members' interests beyond the trade that has seen it become much more representative of the dental industry as a whole.

'Looking ahead, the Association's strategy is clearly focused on developing and delivering those services that will be of greatest business benefit to our changing membership.'

The BDTA is the UK's largest and most authoritative industry body representing manufacturers and suppliers of dental products, services and technologies. Over $20 \%$ of member companies are now involved in business, financial and publishing services. 